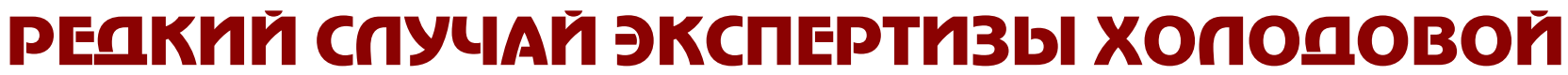 TPABMDI ПPИ CTPEMИTERbHOM TEMחE ПEPEOXПAЖREHHS
}

\author{
К.В. Верещагин \\ Бюро судебно-медицинской экспертизы Московской области (нач. - д.м.Н., проф. В.А. Клевно)
}

Аннотация: Статья посвящена необычному случаю стремительного развития общего переохлаждения при целом ряде способствующих факторов в условиях экстремально низкой температуры окружающей среды при повышенной влажности воздуха. В статье доложен случай из судебно-медицинской практики Дмитровского отделения Бюро судебно-медицинской экспертизы Московской области.

Ключевые слова: стремительное переохлаждение; холодовая травма; биологический нуль

\section{UNCOMMON CASE OF MEDICAL FINDINGS SWIFT HYPOTHERMIA}

\author{
K.V. Vereshchagin
}

Abstract: The article is devoted to the unusual case of the rapid development of hypothermia with a number of contributing factors in extremely low temperature and high humidity. The case of forensic practice of Dmitrov Branch of the Bureau of Forensic Medicine of the Moscow region is reported.

Keywords: swift hypothermia, cold stress, biology zero

$$
\text { http://dx.doi.org/10.19048/2411-8729-2015-1-4-30-33 }
$$

Экспертиза трупов лиц, погибших от действия холодовой травмы, встречается в практике любого судебномедицинского врача-танатолога. При этом диагностика смерти от переохлаждения, как правило, не вызывает каких-либо сомнений в правильности установленного танатогенеза, а сама морфологическая картина имеет обычно целый комплекс характерных макроскопических, микроскопических и биохимических признаков.

Более сложной становится диагностика холодовой травмы при исследовании трупов, которое проводится после длительного нахождения в условиях низкой температуры зимнего периода с чередованием состояний промерзания и оттаивания трупа. Еще более сложной становится диагностика смерти от общего действия холода, когда процесс умирания происходит «стремительно» при комплексе способствующих переохлаждению условий и длительному пребыванию трупа на месте наступления смерти до момента его обнаружения.

Случай из практики Дмитровского РСМО является примером сложности диагностики холодовой травмы вследствие целого ряда особенностей наступления смерти и длительного нахождения трупа на месте наступления смерти, так и правовых обстоятельств.

Гражданин К. после вечеринки в ресторане отправился в частный дом своего отца, где продолжил употребление спиртного. Несмотря на морозную погоду, прием алкоголя осуществлялся в отапливаемой беседке на участке дома. Гр. К. был одет в легкую одежду - не по сезону.

Возраст потерпевшего 25 лет, предшествующий анамнез без особенностей, прошел службу в армии, занимался единоборствами, имел высокий уровень материального обеспечения. В последние несколько лет употреблял спиртные напитки, знакомые и друзья не исключали того, что мог употреблять и «легкие» психотропные средства.

В ходе беседы с отцом обсуждались претензии к бывшему компаньону по бизнесу, уже разделенному между ними. В это время бывший компаньон находился в своем частном доме, примерно в 700 метрах от дома отца гр. К. Между домами пролегает лесной массив с проходящей по нему железной дорогой и протекаю- щей небольшой речкой. Оба дома хорошо освещены уличными фонарями.

Гр. К., сделав подъем переворотом на расположенной у забора перекладине, перескочил через забор из гофралиста, смяв его край, и побежал по тропинке в сторону дома бывшего компаньона со словами «сейчас я с ним разберусь». Время ухода гр. К. из дома - примерно 6 часов утра 18 января 2014 года.

По представленной метеосводке с ближайшей метеостанции, ночная температура в это время составляла $-22,3^{\circ} \mathrm{C}$ с тенденцией к усилению холода, относительная влажность воздуха 85\%, средняя скорость ветра $2 \mathrm{M} / \mathrm{c}$, максимальная до $3 \mathrm{~m} / \mathrm{c}$, осадков не было, зафиксированные атмосферные явления - иней и ледяные иглы.

Отец гр. К. сразу же послал за ним брата, который выехал следом на автомобиле в сторону дома бывшего компаньона, которому был сделан телефонный звонок с предупреждением о том, что к нему выбежал гр. К. с угрозами расправы.

Со слов бывшего компаньона гр. К., в дом к нему никто не звонил и не стучался, о месте нахождения гр. К. ему ничего не известно. Он видел автомашину брата гр. К., которая проезжала мимо его дома.

Брат гр. К. прошел маршрутом пешеходной тропинки от одного дома к другому, обнаружив следы «заваливания» в снег человека, проломленный на неглубокой речке лед с лужей незамерзшей воды. Осмотр прилежащих дорог и окрестностей ничего не дал. Поиски продолжались около 2-3 часов, после чего прекратились в надежде на то, что гр. К. отправился к кому-либо из знакомых, и вскоре вернется. После этого гр. К. живым уже никто не видел.

Правоохранительными органами был выдвинут ряд предположений о возможном убийстве потерпевшего, в частности с использованием электрошокера, который был обнаружен в доме бывшего компаньона при обыске. Также отрабатывалась версия возможного похищения гр. К. Труп был обнаружен подростками, случайно, лишь 10 марта 2014 года в оттаивающем снеге большой ямы у гаражей окраины города, расположенных примерно в одном км от дома, где гр. К. видели последний раз живым (рuс. 1). 


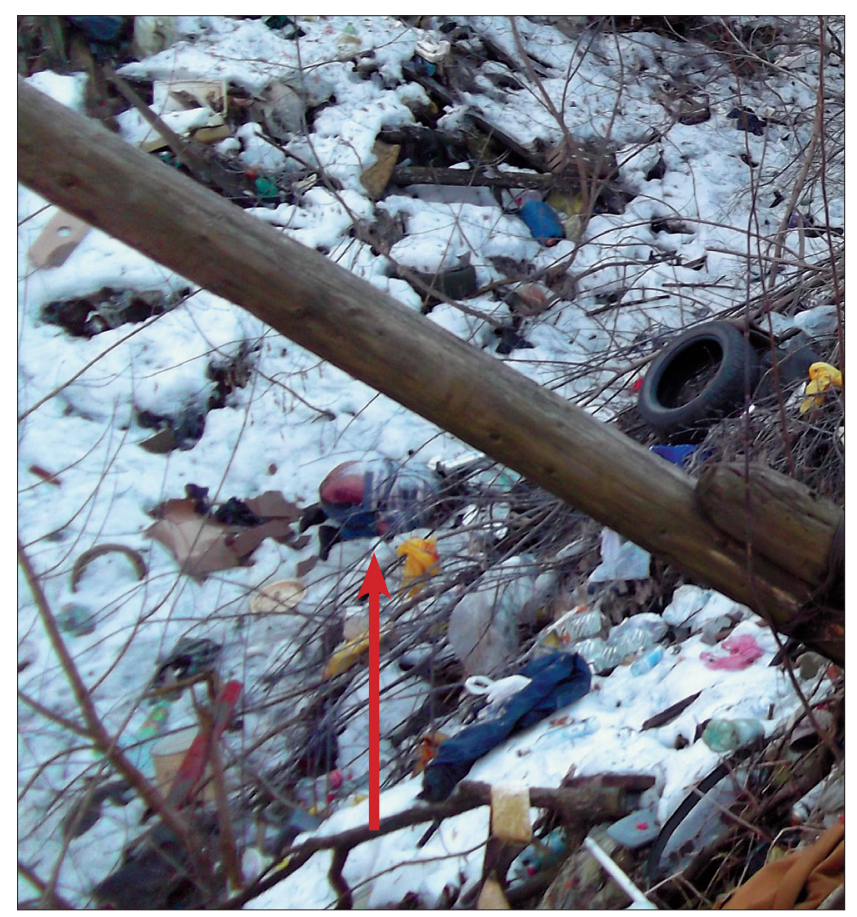

Рис. 1. Общий вид ямы, в которой был обнаружен труп (на рисунке указан стрелкой)

Труп находился в позе «зябнущего» человека, лицом вниз. Яма глубиной около 7-10 метров находилась в плохо освещенной части города за рядами гаражей, циркулярно окружена крутыми склонами примерно под углом в $45^{\circ}$, на склонах и на дне ямы лежал бытовой мусор, росли редкие кустарники и деревья. Для осмотра трупа спуск в яму осуществлялся по приставленной к склону деревянной лестнице. Труп был одет в вывернутый наизнанку легкий трикотажный джемпер, джинсовые брюки на кожаном ремне с металлической пряжкой, трусы, кожаные летние полуботинки на гладкой подошве и трикотажные носки. Одежда не была смещена, имело место лишь небольшое смещение брюк вниз по задней поверхности до крестца (puc. 2).

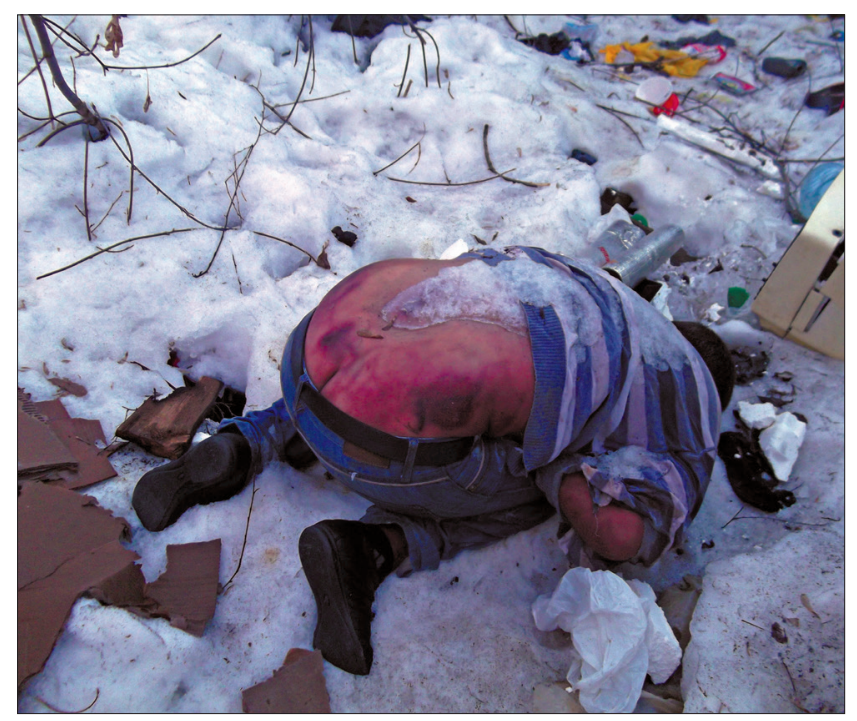

Рис. 2. Поза трупа на месте обнаружения
Одежда была влажной с участками промерзания. Имелись разрывы рукавов джемпера соответственно расположению локтевых суставов и мелкие повреждения ткани брюк со следами размытой крови вокруг.

Были выявлены признаки посмертного объедания трупа животными - отсутствовали мягкие ткани лица и боковых поверхностей головы, шеи спереди, левого предплечья и кисти с характерными морфологическими признаки действия зубов грызунов, без признаков наружного кровотечения вокруг (рuc. 3. 4).
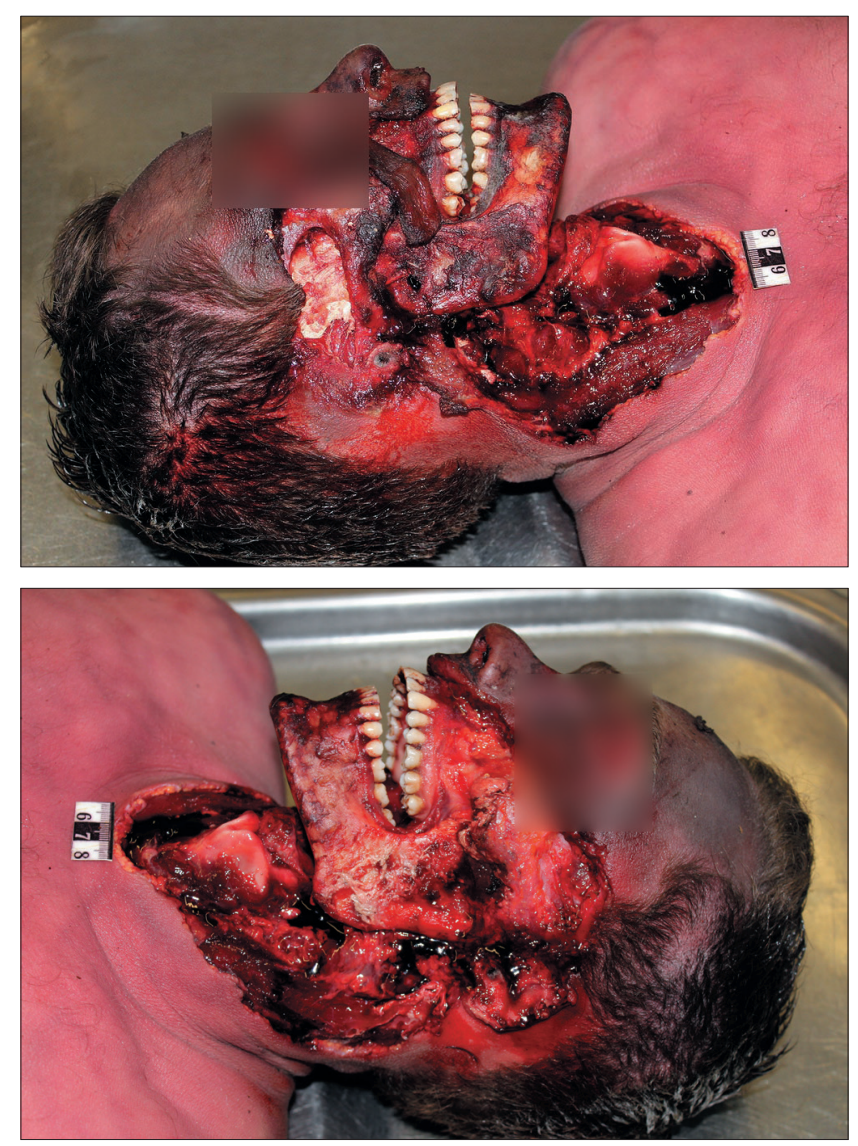

Рис. 3. 4. Общий вид объедания головы и шеи трупа справа и слева.

Указанные области тела были обращены вниз, а под трупом в подтаявшем рыхлом ледяном ложе имелись ходы «туннелей» грызунов. Лицо трупа располагалось в «чаше» подтаявшего снежного покрова.

Мягкие ткани на сохранившихся участках тела были полутвердой консистенции, промерзшие, поза трупа удерживалась жестко вследствие промерзания. Снег под трупом с участками пропитывания его красноватой размытой сукровицей, без признаков наружного кровотечения. Расположение трупных пятен соответствовало позе трупа.

При исследовании трупа в морге после оттаивания были обнаружены множественные мелкие повреждения в виде небольших кровоподтеков и ссадин на туловище и конечностях, расположенных на разных сторонах тела, а также поверхностные ранки ладонной поверхности правой кисти и передней поверхности левого коленного сустава. В месте прилегания пряжки ремня брюк имелся участок ущемленной кожи передней стенки живота с внутрикожным кровоизлиянием, 


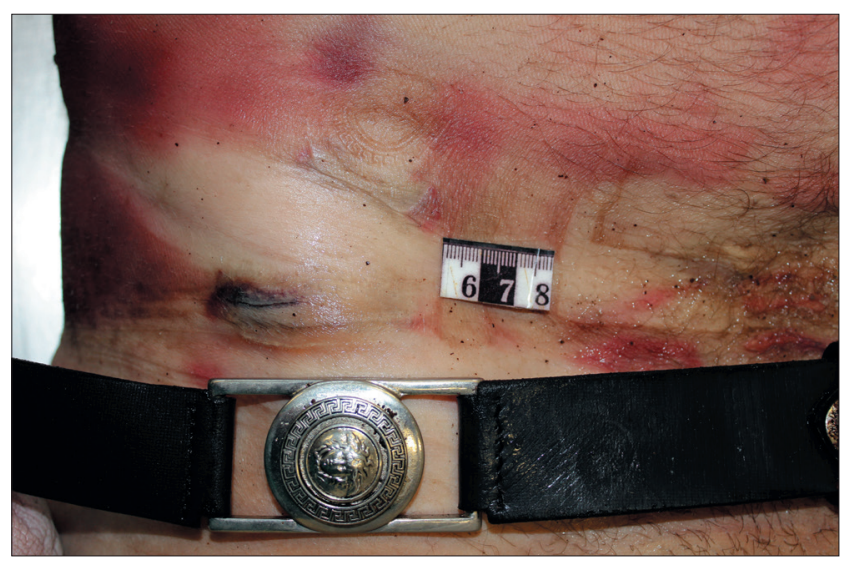

Рис. 5. Защемление кожи передней стенки живота декоративной пряжкой ремня

Были выявлены выраженные признаки мацерации кожного покрова кистей и стоп, определялось сокращение кожи мошонки с поджатием яичек к паховым каналам (рuс. 6).

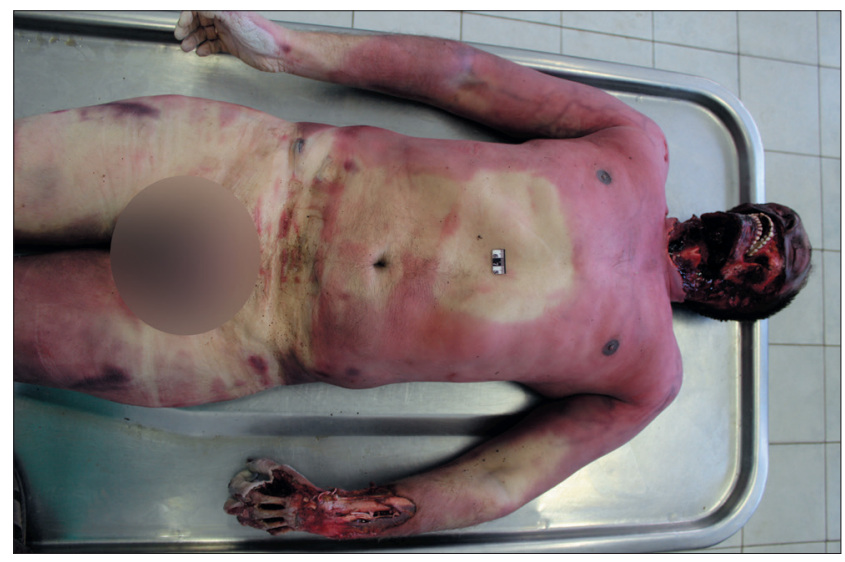

Рис. 6. Расположение трупных пятен на передней поверхности тела, сокращение мочонки с поджатием яичек к паховым каналам

Явных макроскопически видимых признаков ознобления кожного покрова, в том числе и на коленных суставах, обнаружено не было. Повреждений, которые могли бы трактоваться как электрометки, на сохраненных участках кожного покрова обнаружено не было.

При внутреннем исследовании переломов костей скелета, разрывов внутренних органов, повреждений гортанно-подъязычного комплекса, признаков кровоизлияний в рефлексогенных зонах туловища обнаружено не было. Головной мозг был в состоянии аутолиза, плохо держал форму, твердая мозговая оболочка была с розоватым оттенком, мягкая мозговая оболочка с розовато-красным прокрашиванием. Однако состояние головного мозга и его оболочек позволяло установить отсутствие кровоизлияний, как под оболочками, так и в веществе головного мозга. Травмы шейно-затылочного сочленения выявлено не было. В желудке было отсутствие пищевых масс, слизистая желудка была с различимой складчатостью, покрыта бесцветной вязкой слизью с коричневатыми наложениями, после смывания которых в пилорическом отделе желудка были выявлены единичными темно-коричневые расположенные по вершинам складок мелкие очаговые и точечные

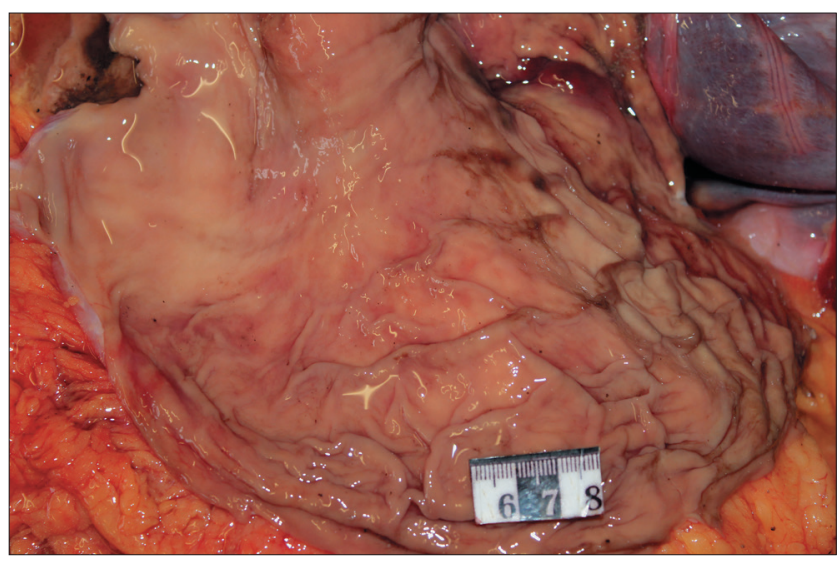

Рис. 7. Единичные кровоизлияния в слизистой желудка по типу пятен Вишневского

Поджелудочная железа была с различимой структурой строения и выраженной дольчатостью. Выявлено повышенное количество пищевого химуса в начальном отделе тощей кишки и отсутствие аутолиза ее стенки при других видах смерти тощая кишка обычно является запустевшей (Верещагин К.В., 2010 г.). В полостях сердца было выявлено большое количество темно-красных рыхлых свертков крови с расширением полостей. В мочевом пузыре 80 мл розовато-желтой мочи. Масса легких составляла 650 и 680 г, явления отека выражены не были, ткань имела красную окраску. На поперечных срезах в просвете главных и долевых бронхов были обнаружены ледяные «столбики» замерзшей слизи.

Проведенное общее химическое исследование установило содержание этилового спирта в крови трупа $1,8 \%$, в моче $2,2 \%$. Наркотических и психотропных средств в крови, моче, желчи и внутренних органах трупа обнаружено не было.

Гистологическое исследование кусочков внутренних органов не внесло какой-либо четкой картины для суждения о причине наступления смерти, вследствие выраженных аутолитических изменений тканей и органов. Описаны кровоизлияния в клетчатке, подлежащей кровоподтекам и ссадинам на туловище, без возможности трактовки давности повреждений. Выявлены отдельные морфологические признаки вторичной кардиомиопатии, жировая дистрофия печени, венозное полнокровие внутренних органов и головного мозга.

При составлении судебно-медицинского диагноза и выводов встал вопрос определения вида смерти, ее доказательства и дифференциальной диагностики с другими возможными причинами.

Известно, что темп умирания при холодовой травме может быть различным и длиться от десятков минут до 8-12 и более часов. При этом условия действия холода, наличие или отсутствие адекватной погоде одежды, головного убора, их влажность и влажность окружающего воздуха, физическое переутомление и состояние алкогольного опьянения могут многократно увеличивать скорость теплопотери организмом, сокращая время развития смертельной гипотермии до 2-3 часов. Также известно, что умирающий от холода человек принимает позу зябнущего человека в условиях, когда его сознание не утрачено полностью, а торможение центральной нервной системы позволяет лишь принять позу, наиболее сохраняющую тепло. При этом люди погибают в той позе, в которой они оказались после потери сознания (Десятов В. П., 1967). Как было указано, труп потерпевшего был обнаружен промерзшим именно в позе «зяб- 
нущего» человека (рис. 2). В то же время невозможно принятие этой позы посмертно, то есть при скидывании трупа в подобную яму.

В нашем случае условия внешней среды отличались ярко выраженной холодовой агрессией - низкая температура до $-22,3^{\circ} \mathrm{C}$ с тенденцией к усилению холода, слабым ветром, ночное время суток перед восходом солнца, когда холодный воздух вследствие своей большей массы свободно заполняет отлогие места и низины местности, вследствие чего температура в них может быть на 5-7 градусов ниже отмеченной на ближайшей метеостанции.

То есть в рассматриваемом случае можно предположить, что потерпевший мог подвергаться действию мороза до $-30^{\circ} \mathrm{C}$. Влажность воздуха составляла $85 \%$, что значительно усиливало действие холода и теплопотерю.

Одежда на потерпевшем абсолютно не соответствовала сезону: тонкий синтетический трикотаж, ставший влажным; отсутствие головного убора при коротком волосяном покрове головы; летняя обувь на тонкой гладкой подошве, что многократно затрудняло возможность самостоятельного карабканья по крутому заснеженному склону, усиливая физическое истощение.

Место обнаружения трупа - с учетом прямого расстояния по карте в 1 км - свидетельствовало о том, что по непрямому маршруту тропинок и извилистых дорог данной части города потерпевший мог преодолеть на морозе около 2 км пути.

Обнаруженная концентрация этилового спирта в крови и моче трупа свидетельствовала об имевшем место алкогольном опьянении, в стадии элиминации алкоголя, что характерно для смерти от общего переохлаждения. Само же опьянение в данном случае выступало фактором ускорения теплопотери. Известно, что в опытах на собаках внутривенное введение 1 мл 96\% алкоголя ускоряло развитие гипотермии на 15\% (Шигеев В.Б., 2004 г.).

Обнаруженные повреждения на трупе не могли послужить причиной наступления смерти, являлись незначительными и были оценены как не причинившие вред здоровью человека. Образование этих повреждений могло быть объяснено как воздействиями твердых тупых предметов по ходу следования потерпевшего через лесопосадку, его прыжками через забор, падениями, заваливанием в заснеженную с бытовым мусором яму и карабканьем по ее склонам.

Учитывая молодой возраст потерпевшего; уровень его спортивной подготовки; наличие отдельных признаков вторичной кардиомиопатии и жировой дистрофии печени, свидетельствующих о небольшом стаже хронической экзогенной интоксикации; отсутствие признаков выраженного отека легких и с учетом обстоятельств наступления смерти, можно было исключить наступление смерти от острой сердечной недостаточности вследствие вторичной кардиомиопатии.
Анализируя обстоятельства случая, следовавшие из материалов дела, выявленные морфологические признаки и данные осмотра места происшествия причиной наступления смерти была установлена холодовая травма. При этом скудность морфологических проявлений переохлаждения не являлась фактом, исключающим данный вид смерти, а наоборот, подтверждала его с учетом установленного темпа переохлаждения при практически максимально полном наборе способствующих факторов - «неподходящая» одежда и ее влажное состояние; отсутствие головного убора и короткий волосяной покров; сильный мороз с температурой более $-20^{\circ} \mathrm{C}$ при высокой влажности воздуха (85\%), слабом ветре; наступление смерти в конце ночного времени суток, когда температура воздуха падает максимально, а холодный воздух скапливается в отлогих местах рельефа местности; физическая нагрузка перед наступлением смерти - длительное бодрствование накануне, последующая пробежка около 2 км пути по пересеченной местности в состоянии алкогольной интоксикации, сваливание в заснеженную яму глубиной 7-10 метров и карабканье по ее склонам. При этом последняя поза потерпевшего - «калачиком» спиной вверх при отсутствии головного убора - максимально открывало для действия холода голову и шейный отдел позвоночника, вследствие чего в терминальной стадии охлаждения «биологический нуль» наиболее быстро мог развиться именно в коре, подкорковых структурах и стволе головного мозга, где значение температуры подавления функции ЦНС составляет $28-30^{\circ} \mathrm{C}$.

Считается, что при чрезмерном охлаждении головы (Аптер Б.А., 1964 г., Ястребов А.П., 1992 г.) и быстром темпе умирания смерть во всех случаях наступает от первичного угасания функции дыхания при еще сохраненной сердечной деятельности.

В данном случае это косвенно подтверждается наполнением полостей сердца темно-красными (без яркого окрашивания) свертками крови и отсутствием выраженного розоватого оттенка легочной ткани на разрезах (что может быть объяснено продолжающимся кровотоком при отсутствии воздухообмена в легких).

Случай был доложен на общей научно-практической конференции Бюро СМЭ, где генез смерти от холодовой травмы был подтвержден подавляющем большинством судебно-медицинских экспертов. Интересен доложенный случай как нетривиальный в общей линейке подобных видов смерти, исследование и доказательство которого было осложнено посмертными аутолитическими изменениями трупа и предшествующей наступлению смерти социальной ситуацией.

\section{$\triangle$ ЛИТЕРАТУРА}

1. Шигеев В.Б., Шигеев С.В., Колударова Е.М. Холодовая смерть. - М.: Новости, 2004.- 183 с.

2. Десятов В.П. Смерть от переохлаждения организма. - Томск: ТГУ, 1977.- 128 с.

ВЕРЕЩАГИН Кенсорин Валентинович - заведующий Дмитровским судебно-медицинским отделением ГБУЗ МО «Бюро СМЭ», главный специалист МЗ МО по судебно-медицинской экспертизе в медицинском округе № 11 . Адрес: 141800, Московская обл. г. Дмитров, ул. Больничная, д. 7. Тел.: 8-495-993-99-45 • E-mail: dr.vereschagin@yandex.ru 